\title{
RA?EGA
}

O ESPAÇO GEOGRÁFICO EM ANÁLISE

\section{O OLHAR DO TURISTA DA ZONA NORTE DE LONDRINA - PR ${ }^{1}$}

\section{THE LOOKING FROM THE TOURIST OF NORTH ZONE OF LONDRINA - PR}

\author{
Andréa Rodrigues dos Santos Beidack ${ }^{2}$
}

\section{RESUMO}

O turismo é uma atividade que integra um conjunto de necessidades da sociedade atual, possibilitando ao ser humano a fuga do corre-corre do cotidiano. Por este motivo, este artigo tem o objetivo de analisar a prática do turismo representada pela população residente na zona norte de Londrina bem como analisar a evolução econômica e social da zona norte no contexto da urbanização da cidade de Londrina e do norte do Paraná.

Palavras-Chave: turismo, fuga do cotidiano, população residente e zona norte de Londrina.

\section{ABSTRACT}

Nowadays, the tourism is an activity that integrate an group of needs of society, becoming possible to the human to escape of the daily routine. For this reason, this work analyze the practice of tourism represented by the north zone of Londrina population. This work also analyze the economic and social evolution of north zone in the context of the urbanization of Londrina city and of the north of Paraná.

KeyWords: tourism, escape of the routine, resident population and north zone of Londrina.

\footnotetext{
1 Trabalho final desenvolvido na disciplina de Turismo e Geografia do Programa de Mestrado em Geografia, Dinâmica Espaço Ambiental da Universidade Estadual de Londrina.

${ }^{2}$ Doutoranda do Programa do Doutorado em Geografia da Universidade Estadual de Maringa. e-mail: deia.be@sercomtel.com.br
} 


\section{INTRODUÇÃO}

Com gênese na década de 1930, a cidade de Londrina passou por um rápido crescimento urbano, intensificado na década de 1970 atrelado às mudanças estruturais no território brasileiro via industrialização e modernização do campo e êxodo rural. Neste período, a atuação do Estado foi intensificada em virtude dos intensos fluxos migratórios que se direcionavam para a cidade e dezenas de conjuntos habitacionais começaram a ser produzidos em todas as direções da cidade.

A zona norte de Londrina emergiu neste contexto, direcionada a abrigar a população que chegava à cidade, esta porção da cidade passou a receber os gigantescos conjuntos habitacionais produzidos pela Companhia de Habitação de Londrina (Cohab-Ld) por intermédio na política federal de produção de moradias para a população de baixo poder aquisitivo através do Sistema Financeiro de Habitação (SFH) e Banco Nacional de Habitação (BNH).

Após a construção dos conjuntos habitacionais e a dotação de infraestrutura o solo urbano na zona norte foi fortemente valorizado e esta porção da cidade passou a ser alvo dos investimentos de capital privado em loteamentos e atividades industriais, comerciais e prestadoras de serviços. Nos dias atuais, a zona norte concentra um forte mercado consumidor de diferentes níveis sócio-econômicos.

Com base no exposto, o presente estudo tem o objetivo de mostrar uma análise da evolução econômica e social da zona norte de Londrina no contexto da urbanização da própria cidade e do país, bem como fazer uma análise da prática do turismo representada pela população residente na área. Inserida na sociedade de consumo de massa, que cria um conjunto de necessidades que devem ser consumidas pelo homem, essa população enxerga na prática do turismo uma possibilidade de fuga do "corre-corre" cotidiano, que representa a vida em uma grande cidade como Londrina. 
A primeira parte do trabalho apresenta uma breve abordagem sobre a história da cidade de Londrina no contexto norte paranaense e brasileiro, na segunda parte, encontra-se uma abordagem sobre o processo de formação e desenvolvimento da zona norte da cidade, popularmente conhecida como "Cinco Conjuntos" e, por último, analisa-se a população residente na área como uma demanda para a prática das atividades turísticas.

Para a elaboração deste trabalho foi necessário, primeiramente, uma pesquisa teórica sobre o Norte do Paraná, em seguida uma análise sobre a produção do espaço urbano da cidade de Londrina e da zona norte da cidade e, por último, uma análise da literatura que envolve a Geografia do Turismo além de outras bibliografias complementares.

Além da pesquisa teórica aplicou-se ainda um questionário para 21 pessoas residentes na zona norte da cidade, de ambos os sexos, idades e ocupações diferenciadas, com a intenção de identificar o que essas pessoas pensam do turismo, se praticam, os lugares que exercem atratividade, a importância dessa atividade entre outras questões.

\section{A CIDADE DE LONDRINA E O NORTE DO PARANÁ}

Para discorrer sobre a zona norte de Londrina é preciso inicialmente remeter-se ao passado da cidade, sua história e constituição, para isso, é mister tecer algumas considerações sobre o norte do Paraná e a CTNP Companhia de Terras Norte do Paraná - colonizadora da cidade de Londrina.

Segundo Alves (1991) o Paraná tornou-se província autônoma após 1853, quando desvinculou-se do estado de São Paulo. Numerosos fazendeiros paulistas e mineiros ocuparam o Norte Velho por volta de 1860, instalando-se nos vales de alguns rios buscavam terras férteis para plantarem o café e outras lavouras. 
Singer (2001) comentou que durante grande parte da República Velha, de 1889 a 1930, São Paulo e Minas Gerais eram os dois estados cafeeiros. A ocupação das terras paranaenses por paulistas e mineiros seguiam os modelos das fazendas cafeeiras desses dois estados, ou seja, eram grandes propriedades, mão-de-obra de imigrantes europeus vivendo em colônias e utilizando técnicas manuais.

Conforme Singer (2001, p. 81) a imigração européia proporcionou "[...] oferta de força de trabalho capaz de suprir a lacuna aberta com a saída em massa dos escravos das fazendas". A imigração era em parte financiada pelo estado de São Paulo. Assim que chegavam, os imigrantes eram diretamente encaminhados para as fazendas de café e submetidos à exploração redobrada.

As terras paranaenses eram adquiridas a baixo custo do governo do estado ou simplesmente ocupadas, fundando vários núcleos urbanos dentre eles a Colônia de Jataí, nas margens do Rio Tibagi, em 1855 (ALVES, 1991). O norte do Paraná começava a ser equipado com infra-estrutura. De 1916 a 1930 a expansão tornou-se ainda mais intensa devido o elevado preço do café no mercado internacional. O governo do estado então decidiu vender as terras do Norte do Paraná para companhias colonizadoras, a fim de que estas parcelassem e vendessem as terras.

A partir da iniciativa de fazendeiros que aí se estabeleceram foi criada a Companhia Ferroviária São Paulo - Paraná, para o escoamento da produção até o Porto de Santos. Em 1924, uma missão inglesa chegou ao Brasil com o objetivo de investir capitais no país, interessaram-se pelo Norte Paranaense. Estava lançada a idéia do empreendimento imobiliário com o nome de Companhia de Terras Norte do Paraná (CTNP).

Entre 1925 a 1927, conforme comentou Alves (1991), a CTNP adquiriu do governo do Estado 515.000 alqueires situados entre os rios Ivaí, Tibagi e Paranapanema. Em 1928, comprou as ações da Companhia Ferroviária São Paulo - Paraná, ampliando a ferrovia. Dividiu a área em glebas e esta em lotes, a cada $15 \mathrm{~km}$ era implantado um patrimônio com uma estação ferroviária. No 
ano de 1929 a CTNP tomou posse de uma grande propriedade e fundou a cidade de Londrina, destinada a ser sede do escritório da companhia.

Através da imensa propaganda pelo interior dos estados do PR, MG e $\mathrm{SP}$, um intenso fluxo de migrantes nacionais e estrangeiros dirigiram-se para esta área. Desmatavam, construíam e plantavam o café e outros produtos. Entre 1920 e 1960, o Norte do Paraná cresceu mais que o restante do estado. Santos (2002) argumenta que por ser front cafeeiro esse estado aumentou sua população de 71,12\% em 1940, para 103,9\% entre 1950 e 1960, já entre 1970 e 1980 ele registrou uma baixa taxa de crescimento, foi quando a fronteira agrícola deslocou-se para as regiões norte e centro-oeste do país.

De 1929 a 1940, Londrina era o ponto convergente da população oriunda de vários pontos do país que procuravam terras para comprar. 0 núcleo central da cidade foi implantado sobre um espigão a oeste do Rio Tibagi, divisor de água entre os ribeirões Cambezinho e Quati, planejado para abrigar uma população de 20 mil habitantes (ALVES, 1991).

Conforme relatou a autora, em 1935 Londrina estava com 700 casas, em 19361.120 casas. Dessa forma, já em 1936 a cidade enfrentou a expansão da malha urbana sobre áreas rurais. A cidade começou a ser procurada não só por agricultores, mas também por aqueles que desejavam encontrar um trabalho no ambiente urbano.

A cidade se expandia física e territorialmente em todas as suas direções devido o intenso aumento de sua população urbana. Ao sul da cidade estavam os terrenos mais caros, reservados para a população de maior poder aquisitivo. Ao norte, os terrenos eram mais baratos, devido à proximidade com a rodovia, sendo destinados à população de baixo poder aquisitivo. À partir de 1940 a falta de moradias tornou-se crescente pois era intensa a chegada de imigrantes. Os proprietários rurais dos arredores parcelavam suas terras produtivas em pequenos lotes visando o mercado imobiliário (ALVES, 1991). 
Segundo Santos (2002, p. 212) a partir de 1950 verificou-se uma aceleração do movimento migratório no país, fenômeno que se intensificou ainda mais nas décadas seguintes. Esse fenômeno foi provocado por fatores como a expansão da mecanização nas atividades agropecuárias o que impulsionou um gigantesco êxodo rural em todo o território brasileiro.

Até o final dos anos de 1960, a cidade de Londrina apresentou rápido crescimento físico-territorial levado à cabo pela iniciativa privada mediante comercialização de lotes urbanos. Desde sua gênese, foi o capital privado quem comandou o processo, seja pela Companhia de Terras Norte do Paraná (CTNP), seja pelos pequenos proprietários rurais, seja ainda pela criação de empresas loteadoras com diversas origens do capital, que promoveram a implantação de projetos ou loteamentos, ampliando ainda mais a área urbana incorporada.

A partir da década de 1970, inúmeras transformações afetaram a cidade e esta passou a ser um dos locais de afluxo da população rural, obrigada a sair do campo, mediante processo de modernização da agricultura. O rápido crescimento populacional urbano agravou as condições de oferta de moradia e articuladamente às tendências nacionais, este período foi marcado em Londrina pela forte atuação do poder público local como ofertador de moradia à população de menor poder aquisitivo através da construção dos conjuntos habitacionais.

Segundo Fresca (2002) a política habitacional comandada pelo poder público local teve início efetivo a partir de 1970, marcada pela atuação da Companhia de Habitação de Londrina (COHAB-LD) criada em meados dos anos de 1960. Á medida que ampliava a demanda por habitação ocorria um crescimento da malha urbana verificada em todas as direções da cidade, principalmente em sentido norte da mesma. Esse direcionamento se deu como estratégia do poder público local em localizar os conjuntos habitacionais naquela área, distante do centro da cidade e com grandes áreas vazias entre os conjuntos e a então malha urbana. 
Fresca (2002) enfatizou que a COHAB-LD iniciou suas atividades construindo os conjuntos habitacionais em Londrina com recursos oriundos do Banco Nacional de Habitação (BNH); tendo no decorrer da década de 1970 entregado à comunidade 30 conjuntos habitacionais, sendo que 11 destes conjuntos foram localizados na porção norte da cidade. A partir de então começou a construção de gigantescos núcleos habitacionais em Londrina como o Parigot de Souza I e II com 1.170 unidades, o João Paz e o Semíramis com 814 unidades, o Aquiles Stenghel e o Vivi Xavier com 1.000 unidades cada, havendo também a necessidade de implantação de infra-estrutura pelo poder público.

Nos anos de 1980, a expansão urbana de Londrina ainda era intensa e a construção dos gigantescos conjuntos habitacionais continuava forte na zona norte com destaque para o Violim com 1.536 unidades e o Maria Cecília com 1.978 unidades, ambos em 1982. Além dos conjuntos habitacionais houve também a expansão de loteamentos da iniciativa privada implantados nos vazios deixados entre a malha urbana e os novos conjuntos da década de 1970. Estes loteamentos foram em sua maioria destinados a uma população de médio poder aquisitivo. No período em tela, houve um aumento dos conflitos sociais em torno da moradia pois parcela da população não tinha condições de adquirir uma casa de conjunto habitacional aumentando o número de favelas e ocupações irregulares.

A partir da década de 1980 houve um aumento significativo da verticalização na cidade, principalmente na área central. A partir dos anos de 1990 até o ano 2000, houve uma dispersão dos conjuntos habitacionais que expandiram-se para todo o entorno da malha urbana, nos sentidos leste, oeste, sul e uma concentração maior na porção norte.

Na primeira década desse novo século a cidade de Londrina continua seu processo de expansão urbana, via abertura de loteamentos, verticalização, ocupações irregulares e conjuntos habitacionais, este último em menor escala se comparado às décadas anteriores. Segundo Estimativas do IBGE no ano de 
2003 Londrina já contava com uma população de 467.334 habitantes. A cidade possui um setor terciário forte compreendendo ramos de atividades diversificadas e tornando-se um importante pólo comercial e prestador de serviços do norte do Paraná.

\section{A ZONA NORTE DE LONDRINA}

A zona norte de Londrina começou a ser produzida a partir da política federal de habitação implementada pelo BNH e o SFH (Sistema Financeiro de habitação) em 1964, com o intuito de amenizar o problema habitacional de grande parcela da população urbana de baixo poder aquisitivo.

Foi no terceiro período de atuação do BNH (1971 - 1979) que houve o incremento de construção de casas populares em conjuntos habitacionais na cidade, principalmente ao norte da então malha urbana (ALVES, 1991). Os primeiros conjuntos habitacionais foram construídos em uma área distante do centro da cidade, deixando enormes vazios entre eles e a então malha urbana.

A estratégia do poder público era localizar os conjuntos habitacionais distantes do centro da cidade, já visando uma valorização futura da área, pois a dotação de infra-estrutura e a implantação de equipamentos de consumo coletivo possibilitaria a ocupação dos vazios deixados entre os conjuntos e o centro da cidade.

Nesse estudo, a zona norte de Londrina foi considerada como a área situada ao norte da BR-369 em quase toda a sua extensão leste e oeste onde a expansão urbana se faz presente, incluindo as direções noroeste e nordeste da cidade, conforme pode ser visualizado no mapa 1 a seguir.

A opção por esta delimitação provém do fato que toda esta área compreendendo o norte, o noroeste e o nordeste da cidade, até a década de 1970, era pouco povoada. A expansão urbana para estas direções da cidade 
foi possível após a retirada da via férrea que, situada no centro da cidade, dificultava uma integração maior deste com a zona norte. A construção de grandes obras de infra-estrutura, como a BR-369, o Estádio do Café, o Terminal Rodoviário, a Avenida Dez de Dezembro, entre tantas outras, contribuíram para a expansão urbana em sentido norte e uma integração desta com o restante da cidade.



Mapa 1 - Localização da zona norte de Londrina

Alguns meios de comunicação da cidade e boa parte da população londrinense passaram a denominar essa área como "Cinco Conjuntos" ou "Cincão", mas os bairros que formam a zona norte nunca foram cinco, os cinco primeiros conjuntos construídos no final dos anos de 1970 foram Ruy Virmont 
Carnascialli, Milton Gavetti, Parigot de Souza I e II, João Paz e Semíramis B. Braga, mas a expressão surgiu somente depois, referindo-se especificamente aos conjuntos Aquiles Stenghel, Luiz de Sá, João Paz, Semíramis B. Braga e Sebastião de Melo César, de acordo com o Engenheiro Civil Luiz Sípoli, exdiretor técnico da Cohab-Ld em entrevista à Folha de Londrina em 2002 (RODRIGUES, 2002).

Com a intensa produção de moradias ocorrida nos anos de 1970, mediante os conjuntos habitacionais houve a formação de um estoque de moradias em uma região distante do centro da cidade, criando-se também enormes vazios urbanos entre a área efetivamente ocupada e os conjuntos. $A$ região passou a receber a instalação de infra-estrutura e equipamentos de consumo coletivo (SILVA, 2002).

Os moradores dos Cinco Conjuntos em sua gênese eram compostos por trabalhadores de várias origens, profissões e ideologias, residindo distante do centro da cidade, reivindicando melhorias nas condições de vida. Essa população que se concentrava nos conjuntos foi trabalhar principalmente no setor terciário da economia (SANTOS, 2002) que tornou-se um grande contratador de mão-de-obra nas grandes cidades. Segundo este autor, em todos os estados da federação aconteceu uma verdadeira explosão no setor terciário entre os anos de 1960 e 1980, apesar de que o trabalho informal também apresentou crescimento significativo.

Os moradores que se sujeitaram a morar nos conjuntos organizaram-se em associações de bairro e foram aos poucos conseguindo do poder público os equipamentos urbanos necessários. Com a região provida de infra-estrutura começou a haver uma relativa alteração social dos residentes nos conjuntos, processo que não ocorreu de forma homogênea, ou seja, não ocorreu em todos os conjuntos. A alteração social foi maior nos conjuntos localizados mais próximos à Avenida Saul Elkind e menor naqueles mais distantes desta avenida. 
Essa alteração social verificada no interior dos conjuntos habitacionais da zona norte se insere em um processo verificado no Brasil em que aconteceu uma redistribuição das classes médias no território. Santos (1993) argumenta que as cidades de porte médio passaram a acolher elevados contingentes de classe média. Um número crescente de letrados, indispensáveis à uma produção material, industrial e agrícola, que se intelectualiza.

A partir de um levantamento realizado através da imprensa escrita, Yamada (1991) relatou como era a situação dos Cinco Conjuntos no início de sua construção e as primeiras décadas de desenvolvimento da referida área.

A zona norte era tida como outra cidade dentro de Londrina, onde a infra-estrutura era insuficiente. O comércio era ainda rudimentar, com gêneros de primeira necessidade. A partir de 1980 o comércio já estava se estruturando e diversificando. A referida área não possuía asfalto e nem iluminação pública, mas aos poucos estes problemas iam sendo solucionados.

Conforme dados de Santos (2002, p. 225) a expansão do meio técnicocientífico-informacional aumenta as necessidades de obter energia elétrica, "não são apenas as demandas de um Brasil industrial mas também a procura representada pelo sistema de transporte, telecomunicações, mecanização da agricultura e informatização das atividades econômicas.

No Brasil urbano de 1975, a iluminação elétrica não era amplamente difundida, nas áreas rurais esse serviço era praticamente inexistente. Dez anos mais tarde a iluminação elétrica já tinha atingido praticamente a totalidade dos domicílios urbanos, cerca de $96 \%$ e na área rural, cerca de 63\% (SANTOS, 2002).

Na década de 1980, conforme citou Yamada (1991), a Avenida Saul Elkind já despontava como o "point" da porção norte, onde os moradores dos conjuntos se encontravam nos finais de semana em bares, restaurantes, festas, etc, para o lazer pessoal e familiar. 
Já no final da década de 1980 muita coisa havia mudado: dotação de infra estrutura, de equipamentos coletivos, ampliação no número de estabelecimentos comerciais e prestação de serviços, aumento no número de habitantes, abertura de loteamentos voltados a diferentes frações da classe média, dentre outros. Foi também aos poucos acabando os preconceitos manifestos na imprensa local referente à população residente na área.

A amplificação de uso e a diversidade social na região, fez com que esta tornasse mais valorizada, atraindo para si investimentos de capitais nos diversos setores como industrial, comercial e prestadores de serviços, todos instalados na Avenida Saul Elkind e em suas proximidades. Esta avenida, da condição de simples localização de comércio rudimentar e artesanal passou a ser o foco dos investimentos de importantes estabelecimentos comerciais e prestadores de serviços localizados no centro da cidade que encontraram na área o local ideal para a instalação de suas filiais, mediante forte mercado consumidor.

A expansão e a intensificação do consumo não foi um acontecimento verificado apenas na zona norte mas em toda a cidade de Londrina assim como em todo o território nacional. Santos (2002, p. 223) salientou que nos últimos vinte anos o Brasil conheceu uma extraordinária expansão dos consumos materiais e imateriais realizada com a cooperação do crédito, um dos principais mecanismos impulsores do consumo. Ressaltou o autor que "A mídia e as instituições financeiras, vetores de um processo de difusão da informação e creditização da sociedade e do território, constituem bases insubstituíveis da criação e expansão do consumo". A expansão da mídia, a indústria cultural e a publicidade exibem propagandas que apelam para 0 consumo.

Nos dias atuais há uma grande concentração e uma intensa variedade de estabelecimentos comerciais e prestadores de serviços na Avenida Saul Elkind reforçando uma valorização dos imóveis implantados nesta avenida ou 
próximos a ela, manifestando uma certa diferenciação nos padrões residenciais locais.

Sendo a zona norte constituída por uma grande diversidade populacional em relação aos níveis de emprego e renda, qual será a percepção dessas pessoas no que se refere às viagens, ao turismo e ao lazer, atividades tão difundidas no atual período histórico em que se verifica uma criação acelerada das necessidades (SANTOS, 1997)? Afinal, quais são as características da demanda turística representada pela população residente na referida região? Tentaremos responder estas questões nas páginas a seguir.

\section{A PRÁTICA DO TURISMO REPRESENTADA PELA POPULAÇÃO DA ZONA NORTE DE LONDRINA}

Para investigar a prática do turismo representada pela população residente na zona norte da cidade aplicou-se um questionário para 21 pessoas residentes em conjuntos habitacionais, loteamentos diversos e condomínios residenciais, com o intuito de conhecer suas preferências e impressões referentes ao turismo. Obteve-se uma gama de ricas informações que pretende-se apresentar a seguir.

O questionário foi aplicado para pessoas de ambos os sexos, compreendendo uma faixa etária entre 14 e 63 anos, contendo profissionais de diferentes áreas como estudantes, auxiliares e técnicos administrativos, pedagogos, professores, entre outros.

Conforme Rodrigues (1997, p. 66) os homens e mulheres como seres individuais e sociais correspondem no turismo, à demanda turística, assim como a população residente e todos os indivíduos responsáveis pelo funcionamento dessa atividade. A demanda turística é originária, em sua maioria, dos centros urbanos, principalmente das metrópoles, deslocam-se 
para lugares distintos dirigindo-se para núcleos receptores onde interage com a população anfitriã.

Mas afinal o que é o turismo? Na opinião dos entrevistados o turismo está relacionado ao ato de viajar, conhecer lugares, povos e novas culturas. É diversão, é fuga de rotina, é lazer, é aventurar-se em áreas desconhecidas, é participar de eventos além de ser também uma importante atividade econômica.

O estudante A. B. G., de 14 anos, comentou que o turismo para ele é "[...] viajar para lugares históricos, interessantes, bonitos e preservados". Para L. C. o turismo é "[...] viagem ou passeio que se faz, onde além de divertimento ganha-se conhecimento e novas descobertas em determinadas áreas e locais". Já S. L. D., 40 anos, enfatizou que o turismo "[...] é uma atividade que envolve o deslocamento de pessoas de um lugar para outro". A professora M. B. S. S., de 29 anos, comentou que o turismo "[...] é toda atividade que envolve um passeio e um novo aprendizado, ou de culturas ou de produtos". A. C. F. N., 40 anos, observou "[...] é uma atividade que se realiza fora da rotina, busca de lazer e qualidade de vida".

Conforme Calvente (2005) a palavra turismo tem origem na palavra francesa "tourisme" que significa volta, viagem ou movimento de sair e retornar ao local de partida. Até o século XIX era uma atividade aristocrática sendo popularizado a partir da criação do turismo de massa, "[...] criação ligada às transformações no mundo do trabalho, com o surgimento das férias remuneradas, a redução da jornada de trabalho, a urbanização e a melhoria nos sistemas de transporte" (CALVENTE, 2005, p. 1 e 2).

A Organização Mundial do Turismo (OMT) assinala que para ser considerado turismo a visita deve resultar na permanência de pelo menos uma noite. Se a visita ocorrer em um período inferior ao de vinte e quatro horas, sem pernoite, a denominação adequada é o excursionismo que "[...] é muitas vezes considerado como uma etapa inicial da atividade, para uma posterior 
adaptação ou construção de alojamentos para pernoites" (CALVENTE, 2005, p. 4).

Rodrigues (1997, p. 80) considera que o "[...] turismo e lazer são atividades simbióticas", ou seja, pode existir lazer sem turismo, porém turismo pressupõe deslocamento e lazer. A categoria mais autêntica de turismo é aquela cuja viagem é o objetivo perseguido.

Para De Mazi (2000) apesar da civilização humana ser sedentária, o ritmo de vida dos cidadãos é marcado pelo vai e vem atrás da profissão e do emprego. Apesar da vida nômade ser uma peregrinação, os nômades cultivam a preguiça e a contemplação. Segundo este autor, o civilizado e o nômade necessitam de um ponto de referência: para um é o lar estável, para o outro um trajeto habitual. Os cidadãos usam como pretexto para suas viagens os negócios ou as férias.

Em relação à freqüência com que os entrevistados praticam o turismo alguns disseram não praticarem o turismo, outros disseram que praticam a atividade pelo menos uma vez ao ano foram poucos os que disseram praticar de duas a quatro vezes anualmente. O período em que costumam praticar o turismo compreende os feriados e as férias de Julho, final e início de ano.

Um aspecto importante que caracteriza a sociedade atual é o tempo livre, De Mazi (2000, p. 139) citando o filósofo russo Alexandre Koyré, comentou que o mesmo escreveu: "[...] não é do trabalho que nasce a civilização: ela nasce do tempo livre e do jogo" argumentou De Mazi que isso pode ter sido verdadeiro no passado, quando se distinguia o trabalho do jogo pois grande parte do trabalho era de natureza física e provocava cansaço.

Segundo o autor o próprio Henri Ford escreveu que não podemos misturar as coisas, ou trabalhamos ou jogamos. Essa distinção há muito tempo perdeu o significado, pois no meio rural, por exemplo, o tempo que o camponês dedicava-se ao trabalho acabava misturando-se às tarefas domésticas e às distrações. Foi a indústria que separou o lar do trabalho e o cansaço da 
diversão. O trabalho tornou-se a categoria dominante na vida humana, subordinando a família, o estudo e o tempo livre. De Mazi acredita que o ser humano deseja possuir os objetos criados pela tecnologia mas o que ele mais deseja é ter tempo disponível para poder usufruí-los.

Os motivos que levam estas pessoas a praticarem o turismo são os mais diversos como a possibilidade de obter o lazer e o conhecimento, o fato de sair da rotina, a diversão, o descanso, a visita a parentes, o fato de curtir a vida, passear, conhecer novos lugares, apreciar a beleza natural entre outros motivos.

Na opinião de J. B., 39 anos, os motivos que o leva a praticar o turismo é "[...] descanso, conhecimento histórico e cultural de nosso país". Para T. C. S. B., 23 anos, "[...] o desejo de estar em contato com a natureza e com coisas alheias ao meu dia-a-dia" a faz praticar essa atividade. A pedagoga S. N. D., 40 anos, argumentou que pratica o turismo para obter "[...] lazer, descanso, curtir a família, cultura, pesquisa, conhecimento histórico", já a estudante A. B. P., 23 anos, citou: "[...] o prazer de estar em contato com algo que não faz parte do cotidiano, é um momento de descontração". A professora M. B. S. S., 29 anos, disse serem os motivos que a levam a praticar a atividade turística "[...] a distração e a possibilidade de respirar novos ares". Um argumento interessante foi o da professora E. N. S. S., 43 anos, que disse ser os filhos o motivo que a leva a viajar.

Verifica-se que as pessoas sentem a necessidade de fugir da rotina do dia a dia, querem viajar, fugir do stress "inventado" (SANTOS, 1997) das grandes cidades. A criação acelerada das necessidades, dentre elas a necessidade do consumir o turismo é o que move a economia atual.

Os movimentos sociais da classe trabalhadora conquistam um tempo livre diário, semanal e anual cada vez maior. Esse tempo é expropriado pela sociedade de consumo de massa que cria novas necessidades. A necessidade imperiosa de viajar é fabricada, sendo incorporada artificialmente ao rol das necessidades básicas do homem (RODRIGUES, 1997, p. 26). 
Tudo parece meticulosamente organizado com muita antecipação pois "[...] cria-se a fábrica, cria-se a metrópole, cria-se o estresse urbano, cria-se a necessidade do retorno à natureza" (RODRIGUES, 1997, p. 30). Onde não há natureza ela é fabricada pelo capital.

Calvente (2005, p. 2) citando a OMT argumentou que segundo esta organização: "[...] a viagem turística pode ter como motivação as férias, o ócio, os negócios, as reuniões, os congressos, as conferências, a saúde, os esportes, a religião, a visita a parentes e amigos, etc."

Segundo Rodrigues (1997, p. 81) desde a antiguidade clássica a viagem para lazer já é conhecida quando representantes das classes urbanas do império romano possuíam duas residências, uma na cidade e outra no campo. Comentou a autora:

Nas sociedades contemporâneas, uma importante motivação da viagem é a necessidade de escapismo, da fuga do cotidiano, pintado pela mídia como monstro criador de neuroses, especialmente urbanas. A viagem prazerosa representa o anti-trabalho, como se a viagem fosse sempre garantia de felicidade e o trabalho fosse sempre algo intolerável (RODRIGUES, 1997, p. 81).

A supracitada autora enfatizou ainda que muitas vezes a viagem é também um meio de adquirir prestígio, um meio promotor do status social. $O$ turismo, antes restrito aos grupos sociais mais privilegiados, atualmente se transforma em um produto da sociedade do consumo de massa.

Nas sociedades pós industriais o turismo, juntamente com o lazer, a cultura, as atividades artísticas, o esporte, a melhoria da qualidade de vida, o hedonismo, compõem um conjunto de elementos que caracterizam um novo estilo de vida, visando cada vez mais a supremacia do indivíduo (RODRIGUES, 1997, p. 81 e 82$)$. 
Assim surge um novo homem, fruto da sociedade de consumo de massa que tem à sua disposição um conjunto de necessidades criadas pelo desenvolvimento técnico-científico-informacional.

No que se refere aos lugares que os entrevistados costumam ir, a maioria respondeu que freqüentam as praias do Paraná e de outros estados, principalmente do sul do país. Outros lugares citados foram chácaras, sítios e fazendas, cidades históricas, serras, campings, locais de pesca, cidades paranaenses e de outros estados além de rios e cachoeiras.

A estudante A. B. P., 23 anos, argumentou: "[...] geralmente vou a sítios, gosto muito de visitar cidades pequenas e também as praias nas férias". A professora M. B. S. S., 29 anos, comentou que gosta de ir "[...] a qualquer lugar que permita distrair-me como sorveteria, shopping, casa de família", A. C. F. N., 40 anos, também citou o shopping center como sendo o local em que costuma ir.

Vale lembrar que se o passeio ao shopping for na mesma cidade, estará mais relacionado apenas ao lazer ou ao excursionismo pois a visita a um shopping não supõe o pernoite. Por outro lado, uma pessoa pode também realizar um turismo se deslocando de um lugar para outro atraída pelos locais de lazer, dentre eles um shopping center, existentes neste lugar de atração.

Rodrigues (1997, p. 35) argumentou que muitas pessoas nos dias atuais, desfrutam do lazer no âmbito doméstico, isso ocorre principalmente nas grandes cidades onde a vida na rua é cada vez mais insegura. Comentou a autora:

Depois da casa, os lugares mais seguros são os shopping centers que procuram na sua artificialidade recriar a vida exterior, simulando ruas, praças, alamedas, bulevares, implementando praças de alimentação e outros equipamentos de lazer como cinemas, discotecas, parques de diversão, circos, pistas de patinação, exibindo shows, desfiles de moda, exposições de arte, só para citar alguns. 
Além de perguntar onde os entrevistados costumam ir quando praticam o turismo, foi também questionado quais são os lugares que exercem atratividade para eles, constatou-se que nem sempre os locais atrativos são os locais que eles freqüentam, talvez isso possa ser explicado pela disponibilidade de tempo, situação financeira e também pelo meio de transporte necessário ao deslocamento.

Alguns citaram ter vontade de conhecer outros países, a maioria frisou ser as praias os locais mais atrativos, tiveram também aqueles que disseram ser atrativas as fazendas, as cidades históricas, as casas de campo, os parques, as matas, as florestas, as cachoeiras, as serras, as áreas com muito verde e os rios, museus e monumentos históricos além de locais com muitos bares e comércio.

A estudante A. B. P., 23 anos, comentou: "[...] gosto muito do campo, geralmente os sítios que freqüento estão localizados próximos a pequenas cidades, que é outra coisa que me chama muito a atenção". A professora $\mathrm{O}$. G. O., 59 anos, citou: "[...] gosto daqueles lugares onde tem muitas pessoas", já $C$. B. H., 29 anos, disse preferir lugares "[...] com pouco fluxo de pessoas, mais isoladas do espaço urbano". A professora C. T. G., 50 anos, foi direta ao afirmar que gosta de lugares "[...] onde tem água", não importa o local, para ela o que deixa o lugar atrativo é a presença de água.

M. A. L., 43 anos, relatou que gosta de "[...] cidades históricas, passeio ecológico, sítios arqueológicos, museus, feiras e festas culturais", enquanto que a secretária L. C. frisou: "[...] gosto de lugares onde posso descansar em contato com a natureza".

A importância da paisagem para o turismo é incontestável, Calvente (2005) comentou que as definições de paisagem partem do ponto de vista de quem a contempla e a analisa, como se a paisagem não existisse sem alguém que a observasse. Conforme Rodrigues (1997, p. 46) "[...] é comum definir 
paisagem como o quadro abrangido pelo campo visual do observador, confundindo-se frequentemente o ver com o perceber.

Conforme a autora, o ser humano percebe o mundo por meio dos sentidos e a eles acrescenta-se a experiência individual construída da bagagem cultural e da história de vida, de sentimentos e pensamentos. Assim, ler a paisagem é muito mais complexo do que ver e perceber a paisagem. Envolve uma visão de mundo, consciente e inconsciente, sempre subjetiva e permeada pelo imaginário. Acrescentou ainda que a paisagem é um notável recurso turístico

[...] tendo em vista que o turista busca na viagem a mudança de ambiente, o rompimento com o cotidiano, a realização pessoal, a concretização de fantasias, a aventura e o inusitado, quanto mais exótica for a paisagem, mais atrativa será para o turista (RODRIGUES, 1997, p. 48).

A paisagem é a forma espacial presente, testemunho de formas passadas que podem ou não persistir, ela resulta de uma acumulação desigual de tempos, encanta e seduz representando artisticamente o mundo visível da cultura. "As cenas bucólicas de uma vida rural idealizada, as florestas tropicais luxuriantes, as tomadas de praias paradisíacas atraem os turistas, ávidos de exotismo, de aventura e de mistério" (RODRIGUES, 1997, p. 49)

Tendo em vista que o turista busca na viagem a mudança de ambiente, o rompimento com o cotidiano, a aventura e o inusitado. Quanto mais exótica for a paisagem mais atrativa será para o turista. Vende-se a imagem com uma dose de fantasia: o verde, a montanha, o pôr-do-sol e a praia. Quanto mais distante for o local mais expectativas o turista vai colocar na viagem, muitas vezes, quando este se depara com o real pode também se decepcionar.

Segundo Urry (1996, p. 146) à partir do final do século XIX houve uma tradição de visitar e conservar o campo com o intuito de apreciar certos tipos de paisagens e majestosas casas de campo, situadas em cenários rurais atraentes. O interesse em visitar o campo também se direcionou em conhecer 
equipamentos e maquinários utilizados na agricultura e os padrões de vida que se desenvolvem no mundo agrícola. Existem inúmeros museus espalhados pelo mundo que retratam a ruralidade.

Os lugares tradicionais também são muito apreciados pelo olhar do turista. $O$ desenvolvimento da tradição envolve a reafirmação de valores que eram antidemocráticos e a exaltação do declínio através de uma repressão à cultura do presente. A proteção do passado disfarça a destruição do presente (URRY, 1996). Muitas vezes a preservação de alguns locais resulta da pressão exercida pelas comunidades locais que procuram manter aspectos de sua história.

São necessárias três condições para que um centro urbano apresentese como uma cidade de tradições: em primeiro lugar, deve haver edificações atraentes e bem preservadas, que representem vários períodos históricos; em segundo lugar, essas edificações teriam de ser destinadas a atividades de alguma maneira consistentes com o olhar do turista e, em terceiro lugar, para que uma cidade se torne plausível do ponto de vista histórico é importante que suas edificações tenham sido significativas do ponto de vista da história, que elas representem ou signifiquem importantes acontecimentos ou processos históricos. Vale lembrar que as antigas edificações não parecem simplesmente velhas mas historicamente importantes, significam que o lugar é antigo e que tem suas raízes na história.

Há ainda o turismo cultural representado pelas artes, teatros, concertos, shows, festivais, futebol, etc. Variados tipos de lugares "[...] passaram a estruturar-se como objetos do olhar do turista; em outras palavras, não como centros de produção ou símbolos do poder, mas como lugares de prazer" (URRY, 1996, p. 170). Quando as pessoas visitam lugares fora das grandes cidades, o que mais as encantam são as edificações apropriadas àquele lugar e que o distinguem de outros.

Em relação aos museus, Urry (1996) comentou que a sociedade atual presencia um crescimento espetacular no número de museus, isto representa 
que o passado está sendo grandemente valorizado. É preciso existir algo extraordinário em relação ao olhar, para ser contemplado. Os museus se preocupam com as representações da história e o que ocorreu foi um aumento do âmbito das histórias dignas de ser contadas.

Há uma tendência no surgimento de vários tipos de museus, incluindo imagens, fotografias, o cinema, museus vivos e até aqueles em que atores interpretam papéis históricos interagindo com os visitantes.

Outro tipo de turismo que também se insere nas preferências do turista é o turismo rural que conforme Calvente (2005, p. 11) que

\section{[...] pode ter como atrativos objetos e costumes herdados do passado, que apresentam um valor simbólico. É um turismo em paisagens naturais e paisagens agrárias, trazendo um retorno ao passado rural ou indígena; é também cultural, de pequenas igrejas e museus, de colheitas, festas, costumes e crenças tradicionais, romarias, artesanato e comidas típicas, valorizando os produtos específicos do local".}

O Brasil é um país que apresenta uma área rural rica e diversificada sendo possível aproveitar as características próprias de cada local, além da riqueza histórica, social, cultural e natural. A atividade turística realizada em áreas rurais têm como motivação o contato com o ambiente rural e uma inter relação com a sociedade local, deve haver a busca dos signos que se identificam com o rural. O objetivo do turista não é só descansar dos rigores do trabalho cotidiano mas também aprender algo e enriquecer-se culturalmente.

Já o ecoturismo, conforme argumentou Rodrigues (1997), caracteriza-se por viagens para reservas naturais com o objetivo de estudar, admirar e desfrutar da paisagem, da fauna e da flora, pretende a integração dos visitantes com o entorno e, particularmente, com as comunidades locais.

Em relação ao meio de transporte utilizado pelas pessoas entrevistadas a maioria disse utilizar veículo próprio (carro) e o ônibus, poucos já viajaram de avião e de motocicletas. O turismo antes restrito aos grupos sociais mais 
privilegiados, hoje se transforma em um produto da sociedade de consumo de massa. Guardadas as devidas proporções todos viajam, desde os que viajam em aviões de luxo até os que viajam em transporte coletivo para a praia mais próxima, ou para visitar um santuário religioso (RODRIGUES. 1997, p. 81).

Ao perguntar se os meios de comunicação e as campanhas publicitárias influenciam na decisão das escolhas dos locais a visitar, a maioria respondeu que sim pois elas incitam a curiosidade além de mostrar os lugares mais bonitos. Outros disseram que a disponibilidade financeira é o fator principal na escolha do roteiro turístico.

Na opinião de C. B. H., 29 anos, os meios de comunicação e as campanhas publicitárias são importantes "[...] porque mostram lugares maravilhosos e perfeitos mas mascaram a violência, a pobreza, etc". J. B., 39 anos, argumentou "[...] me proporcionam um conhecimento maior sobre os pontos turísticos existentes no país". Já C. F. N. comentou "[...] é uma forma de você saber o que o local tem a lhe oferecer".

O auxiliar administrativo A. P., 21 anos, ressaltou que a televisão e a internet, os meios que o mesmo mais acessa, influenciam em suas escolhas dos locais a visitar. Já M. B. S. S., 29 anos, ressaltou que os meios de comunicação e as campanhas publicitárias não influenciam em suas escolhas pois procura conhecer os lugares que tem curiosidade e vontade de conhecer.

Rodrigues (1997) frisou que o espaço criado é reforçado pela mídia que gera e reforça o processo fantasioso, as campanhas publicitárias adentram no universo mental do turista, ela não é apenas um convite à viagem mas um reflexo da mentalidade coletiva. Muitas vezes difunde-se uma imagem de um modo de vida que convém ser imitado pelos seus comportamentos e hábitos de consumo, além de vender-se o espaço turístico como o paraíso.

A prática da atividade turística para a maioria dos entrevistados é realizada com a família, com amigos e também em excursões. Em relação à prática do turismo de eventos, os entrevistados responderam que raramente 
praticam, aqueles que costumam praticar citaram ser de 1 a 2 vezes ao ano. A professora M. B. S. S., 29 anos, frisou "[...] sempre que posso vou a feiras e congressos na cidade de 4 a 5 vezes no ano, fora da cidade de 1 a 2 vezes ao ano.

Segundo Calvente (2005) congressos e simpósios procuram unir reuniões de trabalho com atividades de lazer e pequenas excursões, os participantes vão utilizar a infra-estrutura turística do local como hotéis e restaurantes.

A última pergunta aplicada aos entrevistados foi se consideram a atividade turística importante e por qual motivo, todos responderam que sim pois é o momento em que a família se reúne para descontrair-se, é uma oportunidade de diversão e de fuga das atividades rotineiras, é o momento de descansar, esquecer os problemas, conhecer pessoas e culturas, novos produtos e apropriar-se de novos conhecimentos.

A pedagoga S. N. D., 40 anos, argumentou "[...] além de propiciar conhecimento, lazer, preenchimento do tempo livre, ele movimenta a economia de um país, região, entre outros". G. M. R., 40 anos, frisou que o turismo "[...] aumenta a arrecadação do município e atrai turistas para a cidade". Já A. I. L., 43 anos, relatou que a atividade turística gera novos empregos. O Assistente administrativo J. B., 39 anos, salientou que o "[...] crescimento turístico proporciona o desenvolvimento de vários setores da economia" e A. P., 21 anos, considera que a atividade turística é importante "[...] para formar uma pessoa letrada e culta, sem isso seria impossível".

O turismo pode funcionar como forma de conscientização a partir da observação participativa, com base em experiências autênticas e não programadas. O objetivo é conviver e interagir com a cultura da população residente (RODRIGUES, 1997).

Não há dúvida de que o turismo corresponde nos dias atuais a uma atividade econômica de grande importância. É uma alternativa econômica para 
países em desenvolvimento como o Brasil e que apresenta paisagens belas e diversificadas e um clima bastante favorável permitindo um fluxo contínuo o ano todo, além de que abrem-se perspectivas de emprego para a população.

Vale lembrar que é importante se deter na análise dos custos-benefícios do turismo, a implementação da infra-estrutura, dos equipamentos de lazer, geram custos muito grandes que incidem indiretamente na população local, na forma de recolhimento dos tributos. O custo de vida em uma área turística é mais caro do que o das áreas circunvizinhas, a supervalorização dos imóveis para venda e locação é um dos aspectos mais visíveis; além disso, durante a alta estação o preço dos serviços e do abastecimento é elevado.

Assim como o turismo valoriza o ambiente em algumas vezes também o degrada, os ecossistemas litorâneos como dunas, lagoas, manguezais e coqueirais são os mais susceptíveis à degradação, quanto mais frágil for 0 sistema menor será sua capacidade de absorver as ações externas e ainda pode acontecer a transformação nos valores das comunidades locais.

É indispensável que o turismo e o ambiente sejam estudados de maneira que estejam relacionados de forma a assegurar a compatibilidade entre o desenvolvimento do turismo e a proteção do meio, em todos os seus aspectos físicos, econômico, social e cultural.

\section{CONSIDERAÇÕES FINAIS}

Este trabalho teve o objetivo de analisar a prática da atividade turística pelos moradores da zona norte de Londrina bem como analisar a produção do espaço urbano da zona norte no contexto da expansão físico-territorial da cidade de Londrina inserida no contexto da economia cafeeira que predominou no norte do Paraná no início do século XX. 
A partir da expansão cafeeira e da criação do município, a cidade desenvolvia-se economicamente e aumentava sua população impulsionada pelo forte êxodo rural provocado pela modernização no campo. No bojo do crescimento urbano, inúmeros conjuntos habitacionais e loteamentos diversos foram construídos nas diversas direções da cidade destacando-se a porção norte.

A zona norte foi aos poucos crescendo, recebendo infra-estrutura e tornando-se cada vez mais valorizada, com uma população residente inserida nos mais diferentes estratos sociais e que busca na prática da atividade turística a fuga da rotina cotidiana.

A partir de questionários aplicados a alguns moradores da zona norte, foi possível observar que grande parte das pessoas que aí residem praticam o turismo como forma de lazer, diversão, aquisição de conhecimento, entre outros motivos, consideram a atividade importante tanto do ponto de vista econômico, como social e cultural.

Vale lembrar que o turismo tem se tornado uma prática social importante neste novo século, sendo por isso objeto de estudo de diferentes áreas, dentre elas a Geografia. São inúmeros os locais que apresentam potencialidades e que exercem atratividade sobre o olhar do turista e, em âmbito econômico é uma atividade que a cada dia envolve um maior número de pessoas que vêem na atividade uma possibilidade de emprego e renda.

Enfim, a pesquisa empírica, a bibliografia consultada, as análises e interpretações realizadas permitiram-nos um conhecimento maior a respeito do turismo como uma prática e de sua importância para a sociedade atual.

\section{REFERÊNCIAS}

ALVES, C. L. E. Dinâmica espacial da produção e reprodução da força de trabalho em Londrina: os conjuntos habitacionais. 1991. Dissertação (Mestrado) - Departamento de Geografia, Faculdade de Filosofia, Letras e Ciências Humanas da Universidade de São Paulo, São Paulo. 
CALVENTE, M. D. C. M. H. Turismo e excursionismo rural: potencialidades, regulação e impactos. Londrina: Edições Humanidades, 2004.

DE MASI, D. Tempos pós-modernos: globalizados, criativos e andróginos. In: 0 ócio criativo. Rio de Janeiro: Sextante, 2000.

FRESCA, T. M. Mudanças recentes na expansão físico-territorial de Londrina. Revista do Departamento de Geociências, Londrina, v. 11, oㅡ 2, Julho Dezembro, 2002.

LONDRINA. Perfil de Londrina 2004. PML, 2004.

RODRIGUES, A. B. Turismo e Espaço: rumo a um conhecimento transdisciplinar. São Paulo: Hucitec, 1997.

RODRIGUES, B. Cincão em festa: cinco conjuntos faz 25 anos. Folha de Londrina, Londrina/PR, 8 dez. 2002. Caderno especial.

SANTOS, A feira livre da Avenida Saul Elkind. 2004. Monografia (Bacharelado) - Departamento de Geociências, Universidade Estadual de Londrina, Londrina - PR.

SANTOS, M. A urbanização brasileira. São Paulo: Hucitec, 1993.

SANTOS, M. e SILVEIRA, M. L. (Re) Distribuição da população, economia e Geografia do consumo e dos níveis de vida. In: O Brasil: território e sociedade no início do século XXI. 4. ed. Rio de Janeiro: Record, 2002.

SANTOS, M. Turismo e Lugar: microeconomia, novo planejamento. 1은 Encontro Nacional de Turismo com base local. 1, 2 e 3 de Maio de 1997. Departamento de Geografia da Faculdade de Filosofia Letras e Ciências Humanas da Universidade de São Paulo - SP, duração - 2 horas.

SILVA, W. R. Descentralização e redefinição da centralidade em Londrina. 2002. Dissertação (Mestrado) - Departamento de Geografia, Universidade Estadual Paulista, Presidente Prudente - SP.

SINGER, P. Evolução da economia e vinculação Internacional. In: SACHS, I., WILHEIM, J. e PINHEIRO, P. S. (orgs.). Brasil: um século de transformações. São Paulo: Companhia das Letras, 2001.

URRY, J. Um olhar sobre a história. In: O olhar do turista. São Paulo: Stúdio Nobel, SESC, 1996.

YAMADA, E. R. O setor norte de Londrina: parcelamento urbano e formas de ocupação. 1991. Monografia (Bacharelado) - Departamento de Geociências, Universidade Estadual de Londrina, Londrina - PR. 